\title{
Incidence of complications in secondary alveolar bone grafting of bilateral clefts with premaxillary osteotomy: a retrospective cohort study
}

\author{
Gerhard K. P. Bittermann ${ }^{1} \cdot$ Robert J. J. van Es ${ }^{1}$ • Adrianus P. de Ruiter ${ }^{1} \cdot$ Michael H. Frank $^{2}$ • Arnold J. N. Bittermann ${ }^{3}$. \\ Aebele B. Mink van der Molen ${ }^{4} \cdot$ Ron Koole $^{1} \cdot$ Antoine J. W. P. Rosenberg $^{1}$
}

Received: 20 November 2017 / Accepted: 11 June 2019 / Published online: 26 June 2019

(C) The Author(s) 2019

\begin{abstract}
Objective To evaluate factors affecting incidence of complications after secondary alveolar bone grafting with premaxillary osteotomy (SABG + PO) in children with complete bilateral cleft of lip and palate (BCLP).

Materials and methods Data were collected from children with BCLP treated with SABG + PO from 2004 to 2014 at our institute. Preoperative parameters included age, donor site, race, gingival health, bone quality around cleft-related teeth, premaxilla position, graft timing, presence of canines in the cleft, and presence of deciduous teeth around the cleft area. Logistic regression and the chi-squared test were used to assess correlations and the incidence of complications.

Results In the 64 patients, a significant correlation was found between complication rate and timing of bone grafting with respect to early versus late SABG + PO ( $p=0.041)$, age $>12$ years $(p=0.011$; odds ratio (OR) $5.9 ; 95 \%$ confidence interval (CI) 1.49 23.93), malposition of the premaxilla ( $p=0.042$; OR $3.3 ; 95 \%$ CI 1.04-10.13), and preoperative bone quality around cleft-related teeth $(p=0.005$; OR 5.3 ; $95 \%$ CI 1.6-17.2).

Conclusions The timing of SABG + PO is essential, as early SABG + PO is associated with fewer complications. A malpositioned premaxilla and poor bone quality around cleft-related teeth are associated with more complications. Therefore, preoperative orthodontic repositioning of the malpositioned premaxilla before SABG + PO should be considered.

Clinical relevance Analysis of treatment protocols and complications for BCLP patients underscores that proper timing of SABG $+\mathrm{PO}$ and correct premaxilla repositioning help reduce complications.
\end{abstract}

Keywords Bilateral cleft lip and palate $\cdot$ Secondary alveolarbone grafting $\cdot$ Premaxillary osteotomy $\cdot$ Alveolarcleft $\cdot$ Reoperation . Pediatric dentistry

Gerhard K. P. Bittermann

g.k.p.bittermann@umcutrecht.nl

1 Department of Oral and Maxillofacial Surgery, Wilhelmina Children's Hospital Cleft Team, University Medical Centre Utrecht, Utrecht University, Heidelberglaan 100, PO Box 85500, 3508 AB Utrecht, The Netherlands

2 Department of Oral and Maxillofacial Surgery, Haaglanden Medical Centre, PO Box 432, 2501 CK The Hague, The Netherlands

3 Department of Pediatric Otorhinolaryngology, Wilhelmina Children's Hospital, University Medical Center Utrecht, 3508 AB Utrecht, The Netherlands

4 Department of Plastic Surgery, Wilhelmina Children's Hospital Cleft Team, University Medical Centre Utrecht, Utrecht University, Lundlaan 6, PO Box 85090, 3508 AB Utrecht, The Netherlands

\section{Introduction}

In cleft lip and palate patients, closure of the alveolar cleft involves an autologous bone graft. Secondary alveolar bone grafting (SABG) refers to closure of the alveolar cleft after palatal closing at an early age. However, there are differing opinions concerning the optimal timing and technique for closure of the alveolar cleft in complete bilateral cleft lip and palate (BCLP) patients [1]. In particular, handling of the position of the premaxilla in combination with SABG is technically difficult. Attention must be paid to the repositioning of the premaxilla, harvesting sufficient bone, and ensuring watertight closure of the gingiva $[2,3]$.

Perko [4] and Freihofer et al. [5] suggested a case grouping of SABG with respect to timing, which can be executed with or without a simultaneous premaxillary osteotomy (PO). Early 
SABG takes place before eruption of the canines, and late SABG is performed after eruption of the canines [6]. The term tertiary alveolar bone grafting is used in cases where SABG or osteotomy of the premaxilla has previously failed. PO is defined as an osteotomy of the premaxilla segment in combination with bone grafting and can be scheduled during early or late SABG $[5,7]$.

To define the success of SABG, several relevant parameters have been identified, including the presence of preoperative deciduous teeth around the cleft area, gingival health, a canine present in the cleft area, preoperative position of the premaxilla, preoperative bone quality around the cleft-related teeth, postoperative complications, and revision surgery [5, $8-10]$. It is generally accepted that surgery should ideally be performed before eruption of the permanent canine [6] or before eruption of the lateral incisor, if present $[8,11]$.

Orthodontic pretreatment plays an important role in the surgical outcome of SABG + PO in BCLP patients [12]. Presurgically, the position of the premaxilla and the teeth it bears should be optimized by orthodontic alignment. After SABG + PO, orthodontic treatment aims to move the canine or lateral incisor into the grafted area [13, 14].

Several authors have assessed the clinical outcomes of SABG + PO using various endpoints (Table 1). Reported complication rates range from 10 to $46 \%[2,3,5,8-10$, 14-17]. The only Cochrane review on this issue concluded that there was insufficient evidence for a definite conclusion on SABG because the groups in the articles reviewed were too small to draw any conclusions [18]. We conducted the present retrospective analysis of SABG + PO in BCLP patients to add data from the Department of Oral and Maxillofacial Surgery in the Wilhelmina Children's Hospital cleft team of the University of Utrecht, the Netherlands, to the current literature. This study is aimed at evaluating our treatment protocols for 69 BCLP patients, with a focus on correlations between complications and each of several relevant parameters.

\section{Materials and methods}

This study was a nonrandomized, uncontrolled retrospective consecutive cohort study of all children with a complete BCLP who underwent SABG + PO at the Department of Oral and Maxillofacial Surgery between 2004 and 2014. Patients for whom insufficient surgical data were available were excluded. Patients with some preoperative parameters missing (see below) were included in the analysis. In all, the records of 64 children were suitable for analysis. Follow-up time ranged from 3.1 to 13.4 years. Treatment consisted of SABG with a $P O$ aimed at ages $8-12$ years (range $8-17$ years, mean 11.37 years, standard deviation 1.77 years), ideally at a $67 \%(2 / 3)$ developmental stage of the root of the upper canine or of the lateral incisor, if present.

\section{Surgical protocols}

\section{Primary closure}

The surgical protocol involved closure of the lip at approximately 6 months according to a modified Millard or Tennison technique [19]. In the event of a wide cleft, lip adhesion was performed before closure of the lip. Closure of the soft palate was accomplished according to the procedure described by Sommerlad [20] at 7-9 months. Closure of the hard palate was performed as described by von Langenbeck [21] at 36 years of age. These procedures were performed by plastic surgeons from the cleft team and were not analyzed in this study.

\section{$\mathrm{PO}$ and bone grafting}

Preoperative orthodontic alignment of the alveolar process was conducted in most patients. Orthodontic repositioning of the premaxilla and its teeth was executed if possible. This was performed using removable and/or fixed orthodontic appliances, thus creating a better preoperative frontal dental relationship. The aim of the orthodontic treatment was to align the maxillary segments by expansion of the lateral segments with removable appliances. Orthodontic treatment corrected crowding of the teeth and aligned the upper arch in three segments. The orthodontic treatment did not attempt to correct the vertical or horizontal malposition of the premaxilla.

The surgery was planned using a dental cast model on which a stainless steel splint was manufactured to stabilize the premaxilla during and after surgery. Surgery was carried out under general anesthesia by two experienced surgeons (RK and RvE), and patients were administered prophylactic intravenous clindamycin $13 \mathrm{mg} / \mathrm{kg}$ three times daily from the start of surgery and for 3 days postoperatively. The SABG + PO was performed to achieve a better view of and access to the nasal floor for a watertight closure of the nasal mucosal layer and to reposition the premaxilla. Using this technique, it was possible to place the premaxilla in a vertically and sagittally optimal position, preferably according to an Angle Class I frontal relationship. In all cases, the premaxilla was fixated apically to the vomerine bone with a $0.4-\mathrm{mm}$ stainless steel wire. The alveolar cleft was grafted on both sides during the same surgical procedure. Preferably, a mandibular symphyseal bone graft was used for grafting [22, 23]. If an insufficient quantity of symphyseal bone was observed or if there was a risk of damaging the apical roots of the lower cuspids or incisors, the iliac crest bone was harvested instead. The mucosal layers were closed with slowly resorbing Vicryl 4-0 sutures (Ethicon, Inc., Somerville, NJ, USA). The premaxilla was stabilized with the preoperatively manufactured splint. This splint was semirigidly fixated with stainless steel wires and acrylic resin for at least 6 weeks. During the first postoperative 
Table 1 Surgically related outcome measures and complication rates reported in studies on bilateral clefts treated with premaxillary osteotomy and bone grafting

\begin{tabular}{|c|c|c|c|c|c|c|}
\hline Author & Outcome measures & $\begin{array}{l}\text { Incidence of } \\
\text { complications }(\%)\end{array}$ & $\begin{array}{l}\text { Number } \\
\text { of patients }\end{array}$ & $\begin{array}{l}\text { Study } \\
\text { design }\end{array}$ & $\begin{array}{l}\text { Country of } \\
\text { origin }\end{array}$ & $\begin{array}{l}\text { Follow-up } \\
\text { time }\end{array}$ \\
\hline Present study & $\begin{array}{l}\text { Complications: an adverse } \\
\text { effect directly related to } \\
\text { the surgical procedure }\end{array}$ & 29.7 & 64 & Retrospective cohort & Netherlands & $3-13$ years \\
\hline Scott et al. 2017 & $\begin{array}{l}\text { Success of bone graft, } \\
\text { canine eruption, } f \\
\text { istula, morbidity }\end{array}$ & 27 & 44 & Retrospective cohort & UK & $1.4-14.6$ years \\
\hline Scott et al. 2007 & $\begin{array}{l}\text { Premaxilla mobility, } \\
\text { wound dehiscence, } \\
\text { recurrent oronasal fistulas }\end{array}$ & 20 & 15 & Retrospective cohort & UK & $>3$ months \\
\hline Freihofer et al. 1993 & $\begin{array}{l}\text { Failure: loss of } 50 \% \text { of bone } \\
\text { graft, residual fistulas }\end{array}$ & 15 & 22 & Retrospective cohort & Netherlands & Mean (21 months) \\
\hline Borba et al. 2014 & $\begin{array}{l}\text { Wound dehiscence, infection } \\
\text { of the wound, resorption } \\
\text { of the graft }\end{array}$ & 36 & 71 & Retrospective cohort & Brazil & $\geq 1$ year \\
\hline Jia et al. 2006 & $\begin{array}{l}\text { Bergland criteria and eruption } \\
\text { of the canine }\end{array}$ & 46 & 28 & Retrospective cohort & China & $1-8$ years \\
\hline Shirani et al. 2012 & $\begin{array}{l}\text { Need for revision surgery } \\
\text { because of insufficient } \\
\text { bone height }\end{array}$ & 44 & 44 & Retrospective cohort & Iran & Mean (33.35 months) \\
\hline Carlini et al. 2009 & $\begin{array}{l}\text { Integration of the bone graft, } \\
\text { premaxilla mobility, } \\
\text { residual fistulas }\end{array}$ & 10 & 50 & Prospective cohort & Brazil & 1 year \\
\hline Rawashdeh et al. 2006 & Bergland criteria & 20 & 15 & Retrospective cohort & Jordan & 6 months -5 years \\
\hline Jia et al. 1998 & $\begin{array}{l}\text { Bergland criteria, wound } \\
\text { dehiscence, infection }\end{array}$ & 33 & 55 & Retrospective cohort & UK & $1-10$ years \\
\hline
\end{tabular}

week, the wound was protected with an iodoform-petroleum jelly gauze covered with a zinc oxide-eugenol paste.

\section{Preoperative parameters}

Preoperative baseline data collected included sex, race, and age at time of surgery. Preoperative parameters collected included position of the premaxilla, preoperative bone quality around cleft-related teeth, gingival health, presence of a canine in the cleft, and presence of deciduous teeth around the cleft area. Other data collected included donor site of the graft (chin or iliac crest), timing of SABG (early or late), and follow-up period. All variables except race and the follow-up period were analyzed for correlation with complications. The cases with missing variables were excluded from subgroup analysis.

Four preoperative parameters - preoperative position of the maxilla, timing of the graft procedure, preoperative bone quality, and gingival health — were analyzed as follows:

1. Preoperative position of the premaxilla was evaluated using occlusal radiography and clinical photographs. Xray scans and photographs were assessed initially by two authors $(\mathrm{KB}, \mathrm{RvE})$ until there was a consensus. The results were classified into three categories: reasonable to correct, somewhat displaced, and severely displaced.
Anchor pictures were used to classify the premaxillary positions (Fig. 1).

2. Timing of the grafting procedure was related to the age of the patient and determined using panoramic X-rays to evaluate the developmental stage of the root of the cuspid or of the lateral incisor, if present. If root formation of the cuspid or lateral incisor was 75\% developed, and the position of the cuspid/lateral incisor was one crown length above the occlusal line, it was classified as an impacted cuspid/lateral incisor. If the cuspid/lateral incisor was in the line of occlusion and the root development was > $75 \%$, it was classified as an erupted cuspid. Impacted cuspids were grouped as early SABG. If the cuspid had erupted, it was grouped as late SABG. In the event the cuspid was missing, the lateral incisor was used. Anchor pictures were used as guidelines for classification (Fig. 2).

3. Preoperative bone quality around the cleft-related teeth was estimated using occlusal X-ray scans. Alveolar bone height loss was classified as no bone loss, some bone loss, or severe bone loss. Anchor pictures were used for classification (Fig. 1).

4. Gingival health and oral hygiene were judged using clinical photographs of the dentition. The gingiva was rated healthy, mildly inflamed, or clearly inflamed. Anchor pictures were used for classification (Fig. 3). 
The abovementioned parameters were analyzed twice by $\mathrm{KB}$ and RvE within a time span of 1 year to calculate an intraobserver correlation. A second observer (AR) also analyzed these parameters to calculate an interobserver correlation.

\section{Complications}

A complication was defined as an adverse effect directly related to the surgical procedure. Revision surgery, or reoperation, was defined as surgery that had to be performed after the $\mathrm{SABG}$ and could be related to the SABG procedure.

\section{Statistical analysis}

The baseline characteristics of the 64 patients are reported as categorical variables. Univariate logistic regression was performed to assess the associations between these variables, with a chi-squared test if appropriate. If any trends were noted, receiver operating characteristic (ROC) curve analysis was used to determine the appropriate cutoff values for dividing patients into subgroups. Analysis of variance (ANOVA) was utilized to calculate the difference in average age between the early and late SABG + PO groups. Subgroup analysis was performed for preoperative parameters. SPSS for Mac (release 25.0.0.0, 2017, IBM Corp., Armonk, NY, USA) was used for all statistical analyses. All test statistics were two-tailed, and the significance level was set at $p<0.05$. Inter- and intrarater correlations were calculated using the VassarStats online calculator (vassarstats.net, 2019) to calculate Cohen's weighted kappa.

The strength of agreement was defined as poor agreement (kappa < 0.20), fair $(0.21-0.40)$, moderate $(0.41-0.60)$, good (0.61-0.80), and excellent $(0.81-100)$.

\section{Results}

\section{Baseline characteristics}

Of 69 children with BCLP who had undergone SABG between 2004 and 2014, 65 had undergone SABG + PO. The surgical data of one patient were missing. Thus, 64 cases were suitable for analysis. The timing of $\mathrm{SABG}+\mathrm{PO}$ ranged from 8 to 17 years (mean 11.37 years, standard deviation 1.77 years). Baseline characteristics of the 64 included patients are presented in Table 2. There were 26 girls and 38 boys, with a mean age at surgery of 11.37 years (range 8-17 years); 49 patients were Caucasian and 15 were non-Caucasian. The mean follow-up time was 7.72 years (range 3.113.4 years). The donor site was the iliac crest in 9
(14.1\%) cases and the mandibular symphysis in 55 $(85.9 \%)$ cases. Nineteen patients had complications that included wound dehiscence (three patients), oronasal fistulas (five), total alveolar bone graft loss (six), avascular necrosis of the premaxilla (two), and three other complications (Table 3 ). A detailed analysis of the relationship between preoperative parameters and complications is given below. Revision surgery was required for 18 patients. Four cases were syndrome-related: two cases had ectrodactyly-ectodermal dysplasia-cleft syndrome (OMIM: 129900), one had amniotic band syndrome (OMIM: 217100), and one case had oculogenito-laryngeal(Opitz) syndrome (OMIM: 300000).

Regarding the preoperative parameters, photographs were incomplete for three patients; thus, gingival health could only be scored for 61 patients. Of these, 32 patients were classified in the category as having a healthy gingiva, 27 having a mild inflamed gingiva, and two having clearly inflamed gingiva.

The preoperative position of the premaxilla was evaluated in all 64 patients. The premaxilla was found to be in a reasonable position in 33 patients, in an intermediate position in 27 patients, and in a severely displaced position in four patients.

Among the 63 radiographically evaluable patients, bone quality around the cleft-related teeth was good in 43 patients, fair in 18 , and poor in two patients.

Table 4 shows the weighted kappa values for the inter- and intrarater reliability. The inter- and intrarater weighted kappa values were as follows: preoperative position of the premaxilla $(0.52,0.67)$, timing of grafting $(0.84,0.78)$, preoperative bone quality around the cleft-related teeth $(0.27,0.75)$, and gingival health $(0.62,0.62)$.

\section{Analysis of postoperative complications}

Table 5 shows the relationship of preoperative parameters to encountered complications. Because not all clinical information was retrievable, some parameters were not evaluable in all patients. Because of the small numbers of patients in some categories, some of the aforementioned categories were combined for the analysis. Specifically, "poor" and "fair" preoperative bone qualities around cleft-related teeth were grouped together, as were "intermediate" and "severe" displacement of the premaxilla.

There were three parameters that showed a significant relationship with the rate of complications: preoperative bone quality around the cleft-related teeth ( $p=$ $0.005)$, preoperative position of the premaxilla $(p=$ $0.042)$, and SABG + PO timing $(p=0.041)$. Logistic regression analysis revealed the respective odds ratios (ORs) and 95\% confidence intervals (CIs) for these parameters (Table 6 ). The logistic regression also revealed a significant trend (OR 1.4; 95\% CI 1.013-1.92; $p=$ 
(a) No bone loss

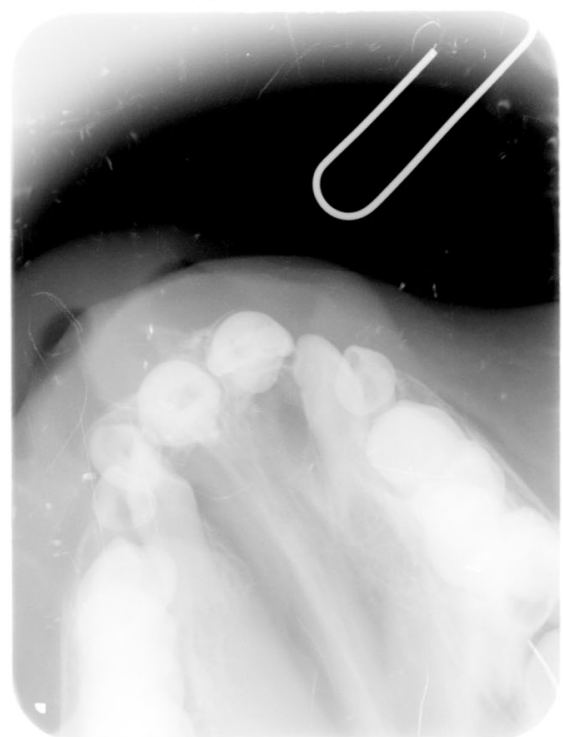

(d) Reasonable to correct

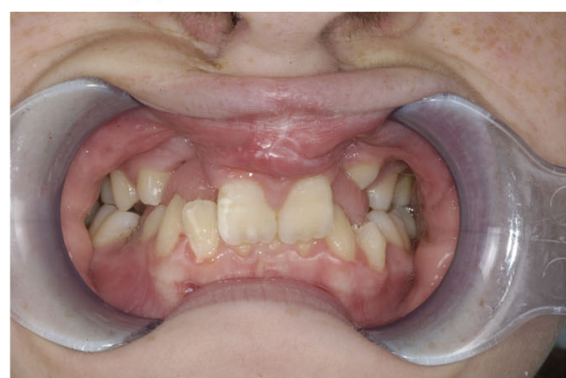

(b) Some bone loss

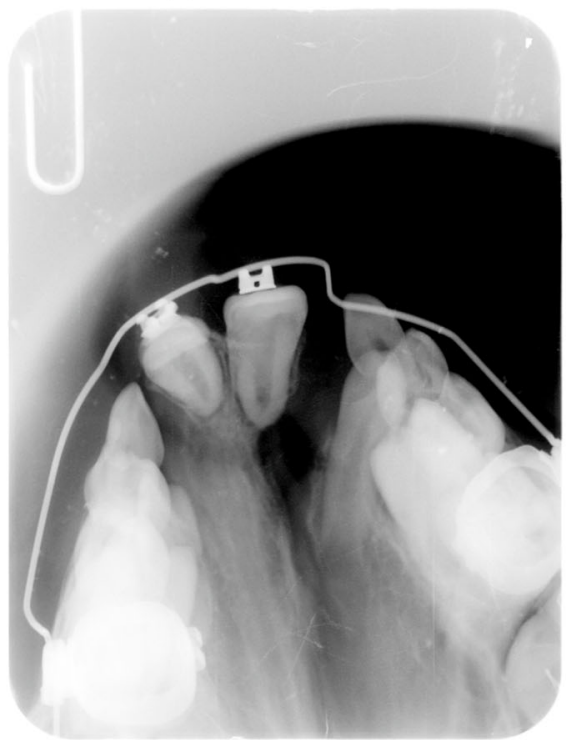

(e) Somewhat displaced

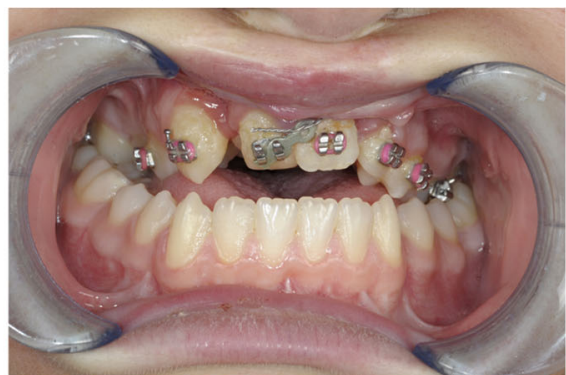

(c) Severe bone loss

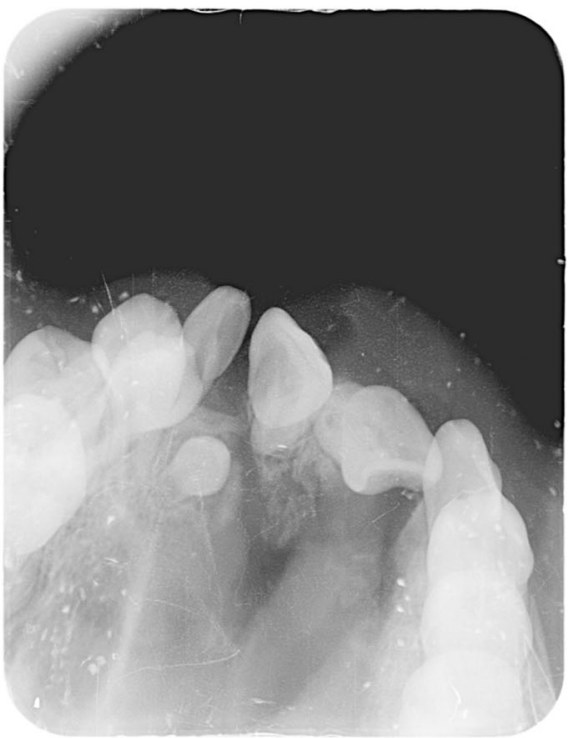

(f) Severe displaced

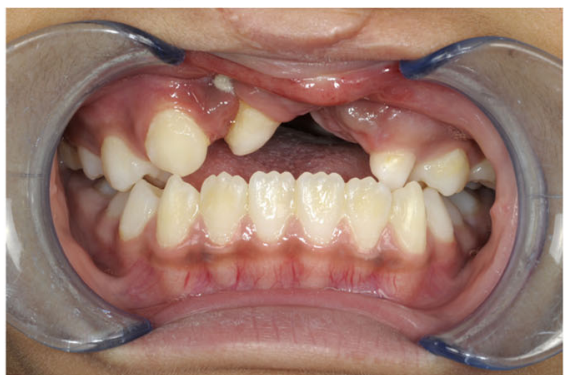

Fig. 1 Preoperative bone quality around cleft-related teeth and preoperative position of the premaxilla. Clinical dental x-rays: a No bone loss. b Some bone loss. c Severe bone loss. Clinical pictures: d Reasonable to correct. e Somewhat displaced. f Severe displaced

$0.041)$ toward more complications at older ages. As expected, the average age of the early $\mathrm{SABG}+\mathrm{PO}$ group differed from that of the late $\mathrm{SABG}+\mathrm{PO}$ group. Early SABG + PO was performed at a mean age of $10.81 \pm 1.39$ years $(n=37)$, and late SABG + PO was performed at $12.19 \pm 2.00$ years $(n=26)(p=0.002$; ANOVA) (Table 7). Therefore, we performed a ROC curve analysis, which revealed a cutoff age of 12 years.

(a) Early secondary alveolar bone graft, before eruption of the canine or lateral incisor
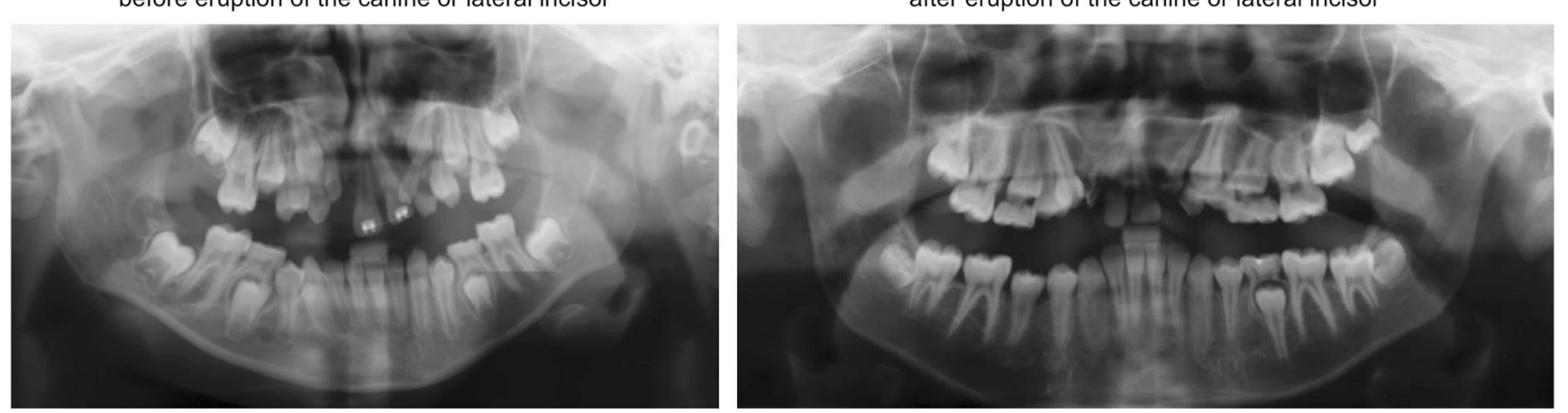

Fig. 2 Time of grafting procedure. a Early secondary alveolar bone graft, before eruption of the canine or lateral incisor. b Late secondary alveolar bone graft, after eruption of the canine or lateral incisor

Subsequent logistic regression showed a significant increase in the rate of complications (OR 5.9; $95 \% \mathrm{CI}$ 1.49-23.93; $p=0.011$ ) among patients $>12$ years of age. Similarly, revision surgery was more frequently necessary in such patients (OR $6.68 ; 95 \%$ CI $1.65-$ 26.99; $p=0.008$ ).

Gingival health appeared to be not related to the incidence of complications (chi-squared $p=0.865$; OR

(b) Late secondary alveolar bone graft, after eruption of the canine or lateral incisor 

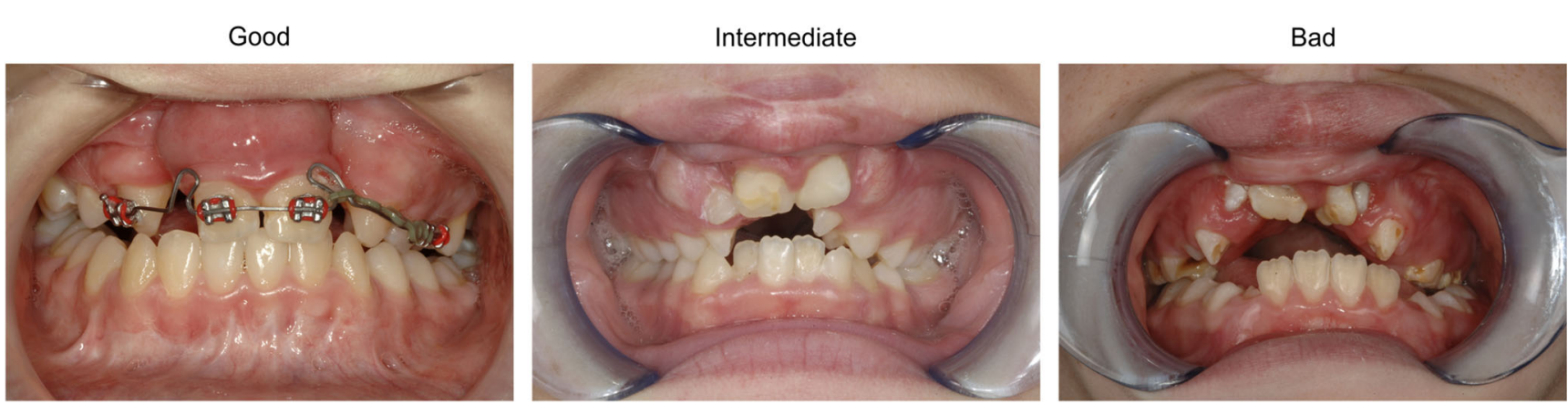

Fig. 3 Gingival health and oral hygiene

$1.1 ; 95 \%$ CI $0.368-3.288$; logistic regression $p=$ $0.865)$.

\section{Discussion}

The present study provides a retrospective analysis of cases of 64 children with BCLP who were treated in Wilhelmina Children's Hospital for closure of their alveolar clefts. This is one of the larger groups of BCLP patients with SABG + PO studied [1, 12]. Our patient group had an overall complication rate of $29 \%$, which is similar to rates reported in previous studies. This study found a significant association between the incidence of complications and the age at surgery, preoperative bone quality around the cleft-related teeth, and preoperative malposition of the premaxilla. Previous reports used different definitions for reporting complications: insufficient bone height of the alveolar process only or patients with residual fistulas $[15,24]$. Complication rates after SABG + PO in BCLP patients $[8,25]$ are reported to vary from 10 to $46 \%$ and are generally higher in bilateral clefts than those observed in unilateral cleft lip and palate patients [10]. In the present study, we defined all variables resulting in an unsatisfactory outcome of alveolar bone graft surgery-i.e., requiring secondary surgery or conservative measures such as antibiotics - as complications.

Our analyses also revealed that the age at surgery had an influence on the complication rate. The subsequent ROC curve analysis revealed a cutoff point of 12 years, above which there was a significant increase in the rate of complications and the need for reoperation. This finding is also in concordance with those of previous studies [8, 24].

\section{Malposition of the premaxilla}

Appropriate orthodontic preparation is an important factor in successful SABG + PO [14]. In particular, widening the narrow alveolar cleft provides better surgical access and easier grafting of the cleft [26]. In the present study, $42 \%$ of patients with a displaced premaxilla required revision surgery, despite semirigid stabilization with a preoperatively manufactured splint. Other authors have also emphasized the substantial effects of preoperative malposition of the premaxilla on the development of complications [27, 28]. The preoperative position of the premaxilla is often displaced or twisted and requires orthodontical or surgical repositioning. After repositioning of a severely displaced premaxilla, it can be difficult to find sufficient soft tissues to achieve watertight and tension-

Table 2 Baseline characteristics

\begin{tabular}{llll}
\hline Variable & $\begin{array}{l}\text { Number of patients } \\
(n=64)\end{array}$ & $\begin{array}{l}\text { Percent of } \\
\text { total }\end{array}$ & Years \\
\hline Preoperative data & & \\
$\quad$ Sex & 38 & 59.4 & \\
$\quad$ Male & 26 & 40.6 & \\
$\quad$ Female & 4 & 6.25 & 11.37 years \\
Patients with syndromes & & & $3.1-13.4$ years (mean: \\
Race & 49 & 23.4 & 7.72 years) \\
$\quad$ Caucasian & 15 & & \\
$\quad$ Non-Caucasian & & & \\
Mean age at time of & & & \\
$\quad$ surgery & & & \\
Follow-up period & & & \\
\end{tabular}


Table 3 Percentage of complications by type

\begin{tabular}{lll}
\hline & Complications $(n)$ & Percent \\
\hline Early major complications with revision surgery $^{\mathrm{a}}$ & 18 & 28.1 \\
Total graft loss & 6 & 9.38 \\
Bone resorption & 1 & 1.56 \\
Wound dehiscence & 3 & 4.69 \\
Bone sequestration & 1 & 1.56 \\
Necrosis of the premaxilla & 2 & 3.13 \\
Oronasal fistula & 5 & 7.81 \\
Late minor complications & 1 & 1.56 \\
Infraposition of the premaxilla & 1 & 1.56 \\
Total complications & 19 & 29.7 \\
\hline
\end{tabular}

${ }^{\text {a }}$ Revision surgery: defined as surgery that had to be performed after the secondary alveolar bone grafting and could be related to this procedure. Except for the case of premaxillary necrosis, this consisted only of wound debridement. Each complication is counted as a separate patient

free closure of the grafted cleft. Watertight and tension-free wound closure decreases the risk of wound dehiscence and prevents perfusion failure of the gingival flaps [2]. Wound dehiscence will subsequently result in infection or loss of the grafted bone [29]. Sindet-Pedersen and Enemark reported that patients undergoing bilateral late SABG had the highest rate of complications $(37.5 \%)$ among their study group [8]. They found that delayed bone healing is mostly related to infection in the grafted region. This is due to the fact that BCLP patients have relatively little mucosal tissue available to cover the grafted area [8, 30].

When SABG is combined with an osteotomy of the premaxilla, the nasal mucosa is more accessible, rendering an easier watertight closure $[1,31]$. The osteotomy can be combined with application of a resorbable membrane such as a collagen membrane. This provides an adequate exposure of the nasal floor and an extra protective layer [2, 27]. Moreover, Shirani et al. described the need for revision surgery in $44 \%$ of their BCLP patients and stressed the importance of a semirigid fixation of the premaxilla after osteotomy and alveolar bone grafting [14]. We therefore believe that preoperative alignment of the malpositioned premaxilla before $\mathrm{SABG}+\mathrm{PO}$ might reduce complication rates. Whether or not to strive for an optimal preoperative orthodontical alignment of the premaxilla will be the subject of further study.

\section{Timing: early versus late}

The ages of 8-11 years are considered appropriate to perform $\mathrm{SABG}+\mathrm{PO}[32,33]$. It is possible to operate even earlier without influencing the growth of the maxilla [30, 34]. The present study demonstrates a significant relationship between late (>12 years) SABG and the development of complications. Previous studies have found a significantly higher complication rate in older patients, especially in the late secondary and tertiary alveolar bone grafting groups [8, 35, 36]. Miller et al. demonstrated that the ideal time for SABG is before eruption of the canine or, if present, the permanent lateral incisor. If the lateral incisor or canine erupts into the grafted cleft, it also results in better residual bone volume after SABG
Table 4 Weighted kappa between interrater and intrarater measurements

\begin{tabular}{llll}
\hline & Weighted kappa & $\begin{array}{l}\text { Standard } \\
\text { error of kappa }\end{array}$ & 95\% CI \\
\hline Intrarater agreement & & & \\
$\quad$ Malposition of the premaxilla & 0.52 & 0.09 & $0.35-0.69$ \\
Preoperative bone quality around cleft-related teeth & 0.27 & 0.06 & $0.14-0.40$ \\
Gingival health & 0.66 & 0.09 & $0.43-0.80$ \\
$\quad$ Time of grafting & 0.84 & 0.07 & $0.70-0.97$ \\
Interrater agreement rater 1 versus 2 & & & \\
Malposition of the premaxilla & 0.67 & 0.07 & $0.52-0.81$ \\
Preoperative bone quality around cleft-related teeth & 0.75 & 0.07 & $0.61-0.88$ \\
Gingival health & 0.62 & 0.09 & $0.45-0.79$ \\
Time of grafting & 0.78 & 0.08 & $0.62-0.93$ \\
\hline
\end{tabular}

Analysis performed by raters 1 and 2 using the VassarStats calculator 
Table 5 Assessment of preoperative parameters and their correlation with incidence of complications: univariate analysis $(N=64)$

\begin{tabular}{|c|c|c|c|c|}
\hline Variable & Category & $\begin{array}{l}\text { Number of patients } \\
\text { (total for variable) }^{\mathrm{a}}\end{array}$ & $\begin{array}{l}\text { Number (\%) of patients } \\
\text { with complications }{ }^{\mathrm{b}}\end{array}$ & $p$ value \\
\hline \multirow[t]{2}{*}{ Sex } & Male & $38(64)$ & $12(31.58)$ & \multirow[t]{2}{*}{0.689} \\
\hline & Female & $26(64)$ & $7(26.92)$ & \\
\hline \multirow[t]{2}{*}{ Preoperative bone quality around cleft-related teeth } & Good & $43(63)$ & $8(18.60)$ & \\
\hline & Poor/fair & $20(63)$ & $11(55)$ & $0.003 *$ \\
\hline \multirow[t]{2}{*}{ Position of the premaxilla } & Reasonable position & $33(64)$ & $6(18.18)$ & \multirow[t]{2}{*}{$0.038^{*}$} \\
\hline & Displaced (intermediate/severe) & $31(64)$ & $13(41.94)$ & \\
\hline \multirow[t]{2}{*}{ Canine present in cleft } & Yes & $18(64)$ & $4(22.22)$ & \multirow[t]{2}{*}{0.358} \\
\hline & No & $44(64)$ & $15(34.09)$ & \\
\hline \multirow[t]{3}{*}{ Gingival health } & Good & $32(61)$ & $10(31.25)$ & \multirow[t]{3}{*}{0.617} \\
\hline & Average & $27(61)$ & $9(33.33)$ & \\
\hline & Bad & $2(61)$ & $0(0)$ & \\
\hline Deciduous teeth around cleft area & Yes & $52(62)$ & $14(26.92)$ & 0.147 \\
\hline \multirow[t]{2}{*}{ Time of grafting } & Early secondary & $37(63)$ & $7(18.92)$ & \multirow[t]{2}{*}{$0.020^{*}$} \\
\hline & Late secondary & $26(63)$ & $12(46.15)$ & \\
\hline \multirow[t]{2}{*}{ Graft type } & Chin & $55(64)$ & $16(29.09)$ & \multirow[t]{2}{*}{0.796} \\
\hline & Iliac crest & $9(64)$ & $3(33.33)$ & \\
\hline
\end{tabular}

${ }^{\text {a }}$ Because of incomplete clinical records, some parameters were not accessible for some patients. The total number of patients for each variable is indicated in parentheses following the number of patients

${ }^{b}$ Percentages were calculated using the number of patients in the corresponding subgroup

* Statistically significant based on the chi-squared test

[11]. Success rates as low as $39 \%$ for groups with the oldest patients and as high as $100 \%$ for groups with the youngest patients have been reported by others [7, 8, 11, 17].

\section{Oral hygiene}

Many BCLP patients appear to neglect their disorder and, consequently, have poor oral hygiene [37]. Moreover, if there is a malposition of the premaxilla and/or crowding of teeth, oral hygiene around the cleft-related teeth is technically difficult also because of the lack of a vestibule in the premaxillary region [38]. Based on the images of gingival health, $35 \%$ of the patients in our population had insufficient oral hygiene. The condition of the gingiva and the graft-covering mucosa seem associated with the success rate of SABG + PO; poor oral health is reported to be a risk factor for infection of the
Table 6 Association between preoperative factors and the likelihood of developing complications: multivariate analysis

\begin{tabular}{llllll}
\hline & $\begin{array}{l}\text { Cases with } \\
\text { complications }\end{array}$ & $\begin{array}{l}\text { Cases without } \\
\text { complications }\end{array}$ & OR & 95\% CI & $\begin{array}{l}p \\
\text { value }\end{array}$ \\
\hline Age versus complications & 19 & 45 & 1.4 & $1.013-1.92$ & $0.041^{*}$ \\
$\begin{array}{l}\text { Age }>12 \text { years versus complications } \\
\text { a }\end{array}$ & 11 & 53 & 5.9 & $1.49-23.93$ & $0.011^{*}$ \\
$\quad \begin{array}{l}\text { Preoperative bone quality around } \\
\text { cleft-related teeth versus complica- }\end{array}$ & 20 & 43 & 5.3 & $1.66-17.21$ & $0.005^{*}$ \\
$\quad \begin{array}{l}\text { tions } \\
\text { Malposition of the premaxilla versus }\end{array}$ & 19 & & & & \\
$\quad$ complications & 18 & 45 & 3.3 & $1.04-10.13$ & $0.042^{*}$ \\
$\begin{array}{l}\text { Age versus reoperation } \\
\text { Age }>12 \text { years versus reoperation }\end{array}$ & 18 & 46 & 1.4 & $1.02-1.97$ & 0.034 \\
Gingival health versus complications & 19 & 46 & 6.68 & $1.65-26.99$ & $0.008^{*}$ \\
\hline
\end{tabular}

CI: confidence interval; OR: odds ratio

${ }^{\text {a }}$ Cutoff age of 12 years was determined by receiver operating characteristic curve analysis

*Statistically significant based on logistic regression analysis 
Table 7 Time of grafting, by age, and significant difference between groups

\begin{tabular}{lllll}
\hline Time of grafting & Number of patients & Mean age (years) & Standard deviation (years) & $p$ value \\
\hline Early secondary & 37 & 10.81 & 1.39 & $0.002 *$ \\
Late secondary & 26 & 12.19 & 2.00 & \\
Missing & 1 & 11.00 & - & \\
\hline
\end{tabular}

*Statistically significant based on analysis of variance bone graft [10]. In the present study, there was a trend toward an increased rate of complications with poor gingival health, but the relationship proved to be not significant.

\section{Bone quality around the cleft}

The present study found a significant relation between preoperative bone quality around the cleft-related teeth and the development of a postoperative complication. However, this has to be interpreted with great care, because the intrarater weighted kappa was 0.27 , which is a poor intrarater reliability. One radiographic study found significant bone loss around teeth at the cleft site in cleft patients [37]. Quirynen et al. found differences between former clefts and adjacent teeth compared with the contralateral nonoperated side. They stated that local factors may influence the condition of the periodontium and the development of gingivitis in cleft patients [39]. Although in unilateral clefts no long-term significant differences between the cleft side and the healthy side were found, there are significant short-term differences in probing depth around the cleft-related teeth and also in the amount of plaque compared with the no cleft side [40]. This is in accordance with our findings, and it is possible that those short-term factors influence the development of complications after SABG + PO.

\section{Preoperative extractions}

If supernumerary or deciduous teeth are present in the cleft area, some authors advise that these teeth be extracted at least 4-6 weeks before the SABG + PO procedure is performed $[11,25]$. This renders the flap designing for graft cover easier, with fewer perforations and less risk of wound dehiscence, resulting in fewer immediate postoperative complications [25]. In the present study population, special attention was paid to the preoperative extraction of deciduous teeth. Therefore, we were unable to analyze the influence of preoperative extractions, as all clefts were already cleared of deciduous teeth.

\section{Limitations}

Because of the retrospective design of this study, clinical data could not be retrieved in some cases and were noted as missing. This methodological flaw may have caused a selection bias in choosing early versus late alveolar bone grafting. The effect of this bias on the outcome remains unclear. The length of follow-up had a wide range of 3-13 years, which may include confounders. In addition, radiological examinations were performed with two-dimensional images, which render analysis of the bone quality around the teeth difficult, resulting in a fair interrater reliability. The results of the bone quality should therefore be interpreted carefully.

It must be realized that this study included a heterogeneous group of patients with BCLP including Caucasians, nonCaucasians, and syndrome-related cases; therefore, the results must be interpreted with caution. Unfortunately, patientrelated outcomes were not available to correlate patient satisfaction with outcomes.

\section{Conclusions}

This study underscores that the timing of $\mathrm{SABG}+\mathrm{PO}$ is essential. Early SABG + PO results in fewer complications than does late SABG + PO and should be preferred. Moreover, a severely displaced and cranially rotated premaxilla is a predictor of complications. Preoperative orthodontic repositioning of the severely displaced and cranially rotated premaxilla might be considered.

\section{Compliance with ethical standards}

Conflict of interest The authors declare that they have no conflict of interest.

Ethical approval The Medical Ethics Committee of the Utrecht University Medical Center approved this protocol (14/417). All procedures performed in studies involving human participants were in accordance with the ethical standards of the institutional and/or national research committee and with the 1964 Helsinki Declaration and its later amendments or comparable ethical standards.

Informed consent Formal consent is not required for this type of study.

Open Access This article is distributed under the terms of the Creative Commons Attribution 4.0 International License (http:// creativecommons.org/licenses/by/4.0/), which permits unrestricted use, distribution, and reproduction in any medium, provided you give appropriate credit to the original author(s) and the source, provide a link to the Creative Commons license, and indicate if changes were made. 


\section{References}

1. Bittermann GKP, de Ruiter AP, Janssen NG, Bittermann AJ, vander Molen AM, van Es RJ, Rosenberg AJ, Koole R (2016) Management of the premaxilla in the treatment of bilateral cleft of lip and palate: what can the literature tell us? Clin Oral Investig 20: 207-217. https://doi.org/10.1007/s00784-015-1589-y

2. Scott JK, Webb RM, Flood TR (2007) Premaxillary osteotomy and guided tissue regeneration in secondary bone grafting in children with bilateral cleft lip and palate. Cleft Palate Craniofac J 44:469475. https://doi.org/10.1597/06-032.1

3. Scott R, Scott J, Stagnell S, Robinson S, Flood T (2017) Outcomes of 44 consecutive complete bilateral cleft lip and palate patients treated with secondary alveolar bone grafting and premaxillary osteotomy. Cleft Palate Craniofac J 54:249-255. https://doi.org/ 10.1597/15-162

4. Perko M (1966) Simultaneous osteotomy of the intermaxillary bone, closure of the residual cleft and strengthening of the intermaxillary bone by secondary osteoplasty in cases of longstanding cleft lip, jaw and palate. Dtsch Zahn Mund Kieferheilkd Zentralbl Gesamte 47:1-5

5. Freihofer HPM, Borstlap WA, Kuijpers-Jagtman AM, Voorsmit RA, van Damme PA, Heidbüchel KL, Borstlap-Engels VM (1993) Timing and transplant materials for closure of alveolar clefts. A clinical comparison of 296 cases. J Craniomaxillofac Surg 21:143-148. https://doi.org/10.1016/S1010-5182(05)80102-7

6. Freihofer HPM, van Damme PA, Kuijpers-Jagtman AM (1991) Early secondary osteotomy-stabilization of the premaxilla in bilateral clefts. J Craniomaxillofac Surg 19:2-6. https://doi.org/10.1016/ S1010-5182(05)80264-1

7. Dempf R, Teltzrow T, Kramer F-J, Hausamen J-E(2002) Alveolar bone grafting in patients with complete clefts: a comparative study between secondary and tertiary bone grafting. Cleft Palate Craniofac J 39:18-25. https://doi.org/10.1597/1545-1569 2002 039 0018_abgipw_2.0.co_2

8. Sindet-Pedersen S, Enemark H (1985) Comparative study of secondary and late secondary bone-grafting in patients with residual cleft defects. Short-term evaluation. Int J Oral Surg 14:389-398. https://doi.org/10.1016/S0300-9785(85)80071-5

9. Borba AM, Borges AH, Da Silva CSV, Brozoski MA, da Graça Naclério-Homem M, Miloro M (2014) Predictors of complication for alveolar cleft bone graft. Br J Oral Maxillofac Surg 52:174-178. https://doi.org/10.1016/j.bjoms.2013.11.001

10. Jia YL, Fu MK, Ma L (2006)Long-term outcome of secondary alveolar bone grafting in patients with various types of cleft. Br J Oral Maxillofac Surg 44:308-312. https://doi.org/10.1016/j.bjoms. 2005.07.003

11. Miller LL, Kauffmann D, St. John D, Wang D, Grant JH III, Waite PD (2010) Retrospective review of 99 patients with secondary alveolar cleft repair. J Oral Maxillofac Surg 68:1283-1289. https:// doi.org/10.1016/j.joms.2009.09.106

12. Geraedts CTM, Borstlap WA, Groenewoud JMM, Stoelinga PJW (2007)Long-term evaluation of bilateral cleft lip and palate patients after early secondary closure and premaxilla repositioning. Int $\mathrm{J}$ Oral Maxillofac Surg 36:788-796. https://doi.org/10.1016/j.ijom. 2007.04.010

13. de Ruiter A, van der Bilt A, Meijer G, Koole R (2010) Orthodontic treatment results following grafting autologous mandibular bone to the alveolar cleft in patients with a complete unilateral cleft. Cleft Palate Craniofac J 47:35-42. https://doi.org/10.1597/08-095.1

14. Shirani G, Abbasi AJ, Mohebbi SZ (2012) Need for revision surgery after alveolar cleft repair. J Craniofac Surg 23:378-381. https:// doi.org/10.1097/SCS.0b013e318240fe7f

15. Carlini JL, Biron C, Gomes KU, Da Silva RM (2009) Surgical repositioning of the premaxilla with bone graft in 50 bilateral cleft lip and palate patients. J Oral Maxillofac Surg 67:760-766. https:// doi.org/10.1016/j.joms.2008.07.013

16. Rawashdeh MAA, Al Nimri KS (2007) Outcome of secondary alveolar bone grafting before and after eruption of the canine in Jordanian patients with cleft lip and palate. J Craniofac Surg 18: 1331-1337. https://doi.org/10.1097/scs.0b013e31814e059b

17. Jia Y-L, James DR, Mars M (1998) Bilateral alveolar bone grafting: a report of 55 consecutively-treated patients. Eur J Orthod 20:299 307. https://doi.org/10.1093/ejo/20.3.299

18. Guo J, Li C, Zhang Q, Wu G, Deacon SA, Chen J, Hu H, Zou S, Ye Q (2011) Secondary bone grafting for alveolar cleft in children with cleft lip or cleft lip and palate. Cochrane Database Syst Rev 6. https://doi.org/10.1002/14651858.CD008050.pub2

19. Millard DR Jr (1960) Complete unilateral clefts of the lip. Plast Reconstr Surg 25:595-605

20. Sommerlad BC (2003) A technique for cleft palate repair. Plast Reconstr Surg 112:1542-1548. https://doi.org/10.1097/01.PRS. 0000085599.84458.D2

21. von Langenbeck B (1861) Operation der angeboren totalen Spaltung des harten Gauments nach einer Methode. Dtsch Arch Klin Med 13:231

22. Koole R (1994) Ectomesenchymal mandibular symphysis bone graft: an improvement in alveolar cleft grafting? Cleft Palate Craniofac J 31:217-223. https://doi.org/10.1597/1545-1569 1994_031_0217_emsbga_2.3.co_2

23. Koole R, Bosker H, van der Dussen FN (1989) Late secondary autogenous bone grafting in cleft patients comparing mandibular (ectomesenchymal) and iliac crest (mesenchymal) grafts. J Craniomaxillofac Surg 17:28-30. https://doi.org/10.1016/S10105182(89)80036-8

24. Calvo AM, Trindade-Suedam IK, da Silva Filho OG, Carvalho RM, de Souza Faco RA, Ozawa TO, Cintra F, Trindade AS Jr, Trindade IE (2014) Increase in age is associated with worse outcomes in alveolar bone grafting in patients with bilateral complete cleft palate. J Craniofac Surg 25:380-382. https://doi.org/10.1097/ SCS.0000000000000639

25. Almasri M (2012) Reconstruction of the alveolar cleft: effect of preoperative extraction of deciduous teeth at the sites of clefts on the incidence of postoperative complications. Br J Oral Maxillofac Surg 50:154-156. https://doi.org/10.1016/j.bjoms.2010.12.007

26. Kindelan J, Roberts-Harry D (1999) A 5-year post-operative review of secondary alveolar bone grafting in the Yorkshire region. Br J Orthod 26:211-217. https://doi.org/10.1093/ortho/26.3.211

27. Koh KS, Kim H, Oh TS, Kwon SM, Choi JW (2013) Treatment algorithm for bilateral alveolar cleft based on the position of the premaxilla and the width of the alveolar gap. J Plast Reconstr Aesthet Surg 66:1212-1218. https://doi.org/10.1016/j.bjps.2013. 04.060

28. Rawashdeh MA, Telfah H (2008) Secondary alveolar bone grafting: the dilemma of donor site selection and morbidity. Br J Oral Maxillofac Surg 46:665-670

29. Van der Meij AJW, Baart JA, Prahl-Andersen B, Valk J, Kostense PJ, Tuinzing DB (2001) Bone volume after secondary bone grafting in unilateral and bilateral clefts determined by computed tomography scans. Oral Surg Oral Med Oral Pathol Oral Radiol Endod 92: 136-141. https://doi.org/10.1067/moe.2001.115274

30. Semb G (2012) Alveolar bone grafting. In: Cobourne MT (ed) Cleft lip and palate. Epidemiology, aetiology and treatment. Front Oral Biol. Karger, Basel, 16:124-136. https://doi.org/10.1159/ 000337666

31. Steinhäuser EW (2014) The modified "Wunderer" osteotomy for stabilization of the cleft-premaxilla - a new operative technique. J Craniomaxillofac Surg 42:372-376. https://doi.org/10.1016/j.jcms. 2014.02.002

32. Borstlap WA, Heidbuchel KLWM, Freihofer HPM, KuijpersJagtman AM (1990) Early secondary bone grafting of alveolar cleft 
defects: a comparison between chin and rib grafts. J Craniomaxillofac Surg 18:201-205. https://doi.org/10.1016/ S1010-5182(05)80411-1

33. Bergland O, Semb G, Abyholm FE (1986) Elimination of the residual alveolar cleft by secondary bone grafting and subsequent orthodontic treatment. Cleft Palate J 23:175-205

34. Padwa BL, Sonis A, Bagheri S, Mulliken JB (1999) Children with repaired bilateral cleft lip/palate: effect of age at premaxillary osteotomy on facial growth. Plast Reconstr Surg 104:1261-1269

35. Meyer S, Mølsted K (2013)Long-term outcome of secondary alveolar bone grafting in cleft lip and palate patients: a 10-year followup cohort study. J Plast Surg Hand Surg 47:503-508. https://doi. org/10.3109/2000656X.2013.789036

36. Newlands LC (2000) Secondary alveolar bone grafting in cleft lip and palate patients. Br J Oral Maxillofac Surg 38:488-491. https:// doi.org/10.1054/bjom.2000.0300

37. Wong FWL, King NM (1998) The oral health of children with clefts-a review. Cleft Palate Craniofac J 35:248-254. https://doi. org/10.1597/1545-1569_1998_035_0248_tohocw_2.3.co_2

38. Lin Y-L, Davies K, Callery P (2017) Experience of maintaining tooth brushing for children born with a cleft lip and/or palate.
BMC Oral Health 17:120. https://doi.org/10.1186/s12903-0170412-3

39. Quirynen M, Dewinter G, Avontroodt P, Heidbüchel K, Verdonck A, Carels C (2003) A split-mouth study on periodontal and microbial parameters in children with complete unilateral cleft lip and palate. J Clin Periodontol 30:49-56. https://doi.org/10.1034/j. 1600-051X.2003.300108.x

40. Perdikogianni H, Papaioannou W, Nakou M, Oulis C, Papagiannoulis L (2009) Periodontal and microbiological parameters in children and adolescents with cleft lip and/or palate. Int J Paediatr Dent 19:455-467. https://doi.org/10.1111/j.1365-263X. 2009.01020.x

Publisher's note Springer Nature remains neutral with regard to jurisdictional claims in published maps and institutional affiliations. 